\title{
From the Good Life to Good Living: A Longitudinal Study Investigating the Relationship Between Good-Life Coherence and Motivation, Goal Progress and Subjective Well-Being
}

\section{Ben Thomas $^{1}$ (D) Kayleigh-Ann Clegg ${ }^{1} \cdot$ Anne Catherine Holding ${ }^{2} \cdot$ Richard Koestner $^{1}$}

Accepted: 5 November 2021 / Published online: 23 November 2021

(c) The Author(s), under exclusive licence to Springer Nature B.V. 2021

\begin{abstract}
Although considerable research has examined the traits and features involved in living a good life (Baumeister et al. in J Posit Psychol 8(6):505-516, 2013; Ryan et al. in Selfdetermination theory: Basic psychological needs in motivation, development, and wellness, Guilford Press, 2006; Wong in Can Psychol/Psychol Can 52(2):69-81, 2011), little research has examined personal philosophies of the good life and the motivational outcomes associated with these views. Through a prospective longitudinal study across one academic year, we examined whether perceiving oneself to be living coherently with personal conceptions of the good life was associated with greater autonomous goal motivation and, subsequently, goal progress and greater subjective well-being (SWB) over time. We hypothesize that perceiving oneself as living coherently in terms of one's own philosophy of flourishing relates to greater volition, goal progress and happiness. Our results suggest that when individuals assess themselves as following their own philosophy of the good life, they tend to experience greater autonomous motivation, goal progress and SWB. Implications for personality coherence and Self-Determination Theory are discussed.
\end{abstract}

Keywords Self-determination theory - Autonomous motivation · The good life · Personality coherence

\section{Introduction}

The good life is a process, not a state of being. It is a direction not a destination (Carl Rogers, 1961, pp. 186-187).

Ben Thomas

benjamyn.thomas@mail.mcgill.ca

Anne Catherine Holding

ach8472@nyu.edu

1 Department of Psychology, McGill University, Montreal, Canada

2 Department of Psychology, New York University, New York city, NY 10003, USA 
In recent years, there has been increased interest in research surrounding the good life and eudaemonia, a term often used to signify what people want most in life (Flanagan, 2007). This is a departure from the scope of traditional psychological concerns that are generally focused on solving psychological distress. As Park and Peterson (2009) suggest, "psychology knows more about people's problems and how to solve them than it does about what it means to live well and how to encourage and maintain such a life" (p. 422). Psychology may struggle in defining the good life but, with Rogers' suggestion, the field can still examine and measure the nature and outcomes of the process itself. Under the Rogerian definition, the good life is the struggle towards coherence between where one is and where they could be; the "process of becoming" that comes about through a greater sense of autonomy and volition (Rogers, 1961, p. 195). In a similar but distinct line of thought, Aristotle suggests that the good life is an ultimate goal that articulates one's personal values and self-beliefs into a concrete vision or destination (Kraut, 2018). In either conception, the good life acts as an indicator of direction, something to strive towards. The present study will investigate the correlates and outcomes of this process of perceived coherence. Namely, does perceiving oneself as living coherently in terms of one's own philosophy of the good life relate to greater volition when pursuing personal goals, greater goal progress, and higher subjective well-being?

\section{Examining Personal Philosophies of the Good Life}

Although considerable research has examined what makes a good life (Baumeister et al., 2013; Ryan et al., 2006; Wong, 2011), few studies have measured personal philosophies of the good life and the process of following them. This inquiry is suggested by Laura King, who proposes that asking individuals about their philosophies of life could prove to be a promising future direction in motivational literature (King, 2001, p. 805). The question remains as to whether or not personal philosophies and abstract beliefs (e.g., "world peace", "justice", "truth"), when reflected and experienced through current functioning, are associated with psychological health and well-being.

We propose that personal philosophies of the good life reflect personally significant beliefs and values. In The Nicomachean Ethics, Aristotle claims that no individual attempts to lead a good life in order to fulfill some further goal (Kraut, 2018). Instead, other goals serve as subordinate strivings when compared to the goal of living well. In this sense, we can consider the good life as the ultimate goal; as a projected future vision that articulates the integration of our values and motives. This idea is evident in McAdams (2018, p. 213) reflections on the good life: "moral values articulate visions for what a good life might be...These imagined end states may be projected into the future, like goals".

Under the cybernetic view of personality coherence, this Aristotelian view of the good life as the ultimate aim is worth examining. The cybernetic approach tends to conceptualize goals within a hierarchy of functioning. The highest level of the hierarchy contains system values. These are highly abstract goals (e.g., "Live a good life") that offer reference values for lowerlevel goals, defined as principles (e.g., "Open yourself up to more experiences"), which then provide guidance for lower programs (e.g., "Travel to a foreign country") and sequences (e.g., "Buy plane tickets to Mozambique") (Powers, 1973; Fournier et al., 2015, p. 257). Personal philosophies of the good life may represent these higher levels system values and principles that occupy the top of the hierarchy of goals. 


\section{Psychological Benefits in Following Higher Order Values and Principles}

If subjective views of the good life reflect these personally significant beliefs, then individuals should benefit from living coherently with their ideas of the good life. This hypothesis is reflected in previous research that has examined similar hierarchically organized concepts. For example, Sheldon and Kasser (1995) found that participant-rated coherence between lower-level personal strivings and higher-order possible futures, called 'vertical coherence', was associated with greater vitality and self-actualization. Similarly, Bauer and McAdams (2004) found that higher-order life growth goals that cohered with lower-order everyday growth goals were associated with greater social-cognitive maturity and socialemotional well-being.

These studies were concerned with vertical coherence and, similarly, this present study will examine participant-rated vertical coherence between philosophies of the good life and perceived current living. Specifically, we will measure the extent to which one is coherently living their good life through self-report. Previous research does suggest that individuals value the subjective feeling of self-knowledge and that measuring a person's selfbeliefs, whether accurate or not, is still an indicator of several psychological outcomes (Shlegel et al., 2011). Hence, we suggest that perceived good life coherence-which we define as an individual's subjective assessment of coherence between their current life and their personal philosophy of the good life-is a suitable indicator of whether or not someone is living coherently with their view of the good life.

Perceived good life coherence is conceptually similar to Sheldon's Self Concordance Model or SCM (2014) as it relates to coherence between one's values and lived experience. The SCM focuses on the importance of pursuing goals that reflect an individual's authentic self and hinges on accurate self -insight (Sheldon, 2014 p. 10). Indeed, individuals who demonstrate self-insight in terms of greater trait-mindfulness (Sheldon, 2004), or possess proactive personalities (Bateman \& Crant, 1993) are better able to select autonomous goals. Autonomous reasons for pursuing a goal include doing so because it is interesting or enjoyable (intrinsic), because the goal represents one's values and beliefs (integrated), or because the goal is inherently important to the individual (identified). Autonomous reasons for pursuing a goal are contrasted with controlled reasons which include pursuing a goal to avoid feelings of shame or guilt (introjection) or to obtain specific outcomes linked to rewards or the absence of punishment.

When people pursue goals that are aligned with their underlying values, talents, interests, and needs (i.e., autonomous goals), they are more likely to make progress on and attain their goals (Holding et al., 2017; Koestner et al., 2002, 2008; Sheldon \& Elliot, 1998 ) rather than getting distracted by competing desires (Milyavskaya et al., 2015) or getting stuck in goal conflicts (Holding et al., 2017). Although some evidence suggests that autonomous motivation is directly associated with increased subjective well-being (SWB) (Sebire et al., 2009), a considerable amount of research also shows that goal progress, which tends to result from autonomous goal striving, is associated with increased SWB (Klug \& Maier, 2015). Hence, autonomous motivation appears to enhance well-being through direct and indirect paths (Hope et al., 2019).

While accumulating evidence supports the benefits of pursuing and attaining autonomous goals (Holding \& Koestner, 2021; Sheldon, 2014), less research has investigated conditions that are conducive to autonomous goal pursuit. Similar to the SCM, we theorize that the perception of living coherently with one's philosophy of the good life reflects 
a form of self-insight beneficial to heightened autonomous motivation for one's personal strivings. Carrying out one's life philosophy suggests that one is capable of integrating abstract values and goals with a more concrete vision; a process that is arguably reliant on accurate self-insight. Overall, we hypothesize that perceiving oneself as living coherently in terms of one's own philosophy of flourishing relates to greater volition, greater goal progress, and greater well-being.

\section{The Present Study}

Through a prospective longitudinal study across one academic year, we examined whether perceiving oneself to be living coherently with personal conceptions of the good life was associated with greater autonomous goal motivation and, subsequently, greater goal progress and greater subjective well-being (SWB) over time. At the beginning of the year, we had participants describe their view of good life, rate the extent to which their current life reflected their good life, set three personal goals for the academic year, rate their motivation for pursuing these goals, and rate their SWB. At the end of the first academic semester (T2), we re-assessed goal motivation and also assessed participants' goal progress. At the end of the academic year, we re-assessed participants' SWB. We expected perceived good life coherence to be positively associated with autonomous motivation for personal goals, personal goal progress and changes in SWB. Given that autonomous goal motivation is considered an antecedent of goal progress (Holding et al., 2017; Koestner et al., 2008), and that goal progress has been robustly associated with enhancing SWB (Klug \& Maier, 2015), we sought to test a serial mediation model examining the effects of perceived good life coherence on changes in SWB through the effects of changes in autonomous goal motivation and participants' goal progress.

\section{Methods}

\subsection{Participants}

A sample of 231 students from a North American university were recruited through posters around campus to participate in a year-long 3-wave prospective goal study. The age of the participants ranged from 17 to $38(M=19.81, S D=2.36)$. The sample was primarily female (84\%). 1 participant identified as a trans male and 1 identified as 'other'. The demographic was composed of various ethnicities (51\% Caucasian, 18\% East Asian, and $31 \%$ other). Overall attrition across all 3 waves was approximately $13 \%(N=231$ at $\mathrm{T} 1$ to $N=201$ at T3). Survey 1 was given at the start of the academic year (T1), Survey 2 was completed halfway through the year (T2), and Survey 3 was completed at the end of the year (T3). This study and the results that were collected occurred before the COVID-19 pandemic.

\subsection{Measures}

Perceived good life coherence. Participants were asked to respond to the following prompt at T1: Please provide a two-sentence description of what you would consider to be the 'good life'. Due to the open nature of this question, answers varied in length and 
content. A set of good life statements can be found on "Appendix 1". Below is a smaller sample of statements from three different participants to give a sense of the considerable diversity:

1. "Being in the position to be able to institute meaningful change on a large scale and effectively tackled the issues that I care about. Also being surrounded by people I care about who care about me in return".

2. "Feeling successful in the field I chose to pursue and surrounded by the people I love the most".

3. "Retire young and rich. Exercise daily and eat nutritious foods, take supplements and drugs that aid longevity e.t.c. Live in a prestigious city that has plenty of sun. Have at least two kids".

It should be noted that participants were deliberately given the freedom to articulate their view of the good life. This typically resulted in individuals either responding to the prompt with a philosophical frame (A good life is...) or through a personal-goal frame (I want...). Throughout the paper, the content of these statements will be interchangeably referred to as goals or beliefs due to the diversity in framing. Participants were then instructed to rate the extent to which their current life reflects their good life statement on a 1-7 scale anchored "Not at all" to "Completely". We have termed these ratings perceived good life coherence.

Selection of personal goals. Participants were instructed to set three personal goals for the academic year at T1 following the prompt used by Koestner et al., (2008). These goals were generated without reference to the good life. Below are three different goals from three different participants:

1. I want a 3.5 GPA.

2. I want to meet several good friends whom I can really talk with.

3. Get better at roller-derby and pass the bootcamp.

Goal motivation. At T1 and T2, goal motivation was measured in terms of people's reasons for pursuing their goals (Sheldon \& Elliot, 1998). Participants rated their motivation for pursuing each of their three generated goals with five items that assessed autonomous (identified, integrated, and intrinsic) and controlled (external and introjected) reasons for goal pursuit. All responses were made on a 7-point scale of 1 (not at all for this reason) to 7 (completely for this reason). As in previous studies, autonomous motivation was calculated as the mean of intrinsic, integrated, and identified ratings (Koestner et al., 2008).

Goal progress. Goal progress was measured at T2 as an average across three items for each goal that each individual initially provided at T1. This was assessed using a previous measure for student goal progress (e.g. Koestner et al., 2002), which included items like: I have made a lot of progress toward this goal. All ratings were made on a 7-point scale ranging from 1 (strongly disagree) to 7 (strongly agree). Scores were averaged across the three goals for the purposes of this study.

Subjective well-being. We employed the Mood Report (Diener et al., 1985) to assess the emotional component of SWB. Sample items from Mood Report include 1. Joyful, 2. Unhappy, 6. Pleased, 9. Frustrated. The five-item Satisfaction with Life Scale (SWLS; Diener et al., 1985) was employed to assess the cognitive component of SWB. 
A composite index of SWB was calculated with the mean scores of positive affect, reversed negative affect, and satisfaction with life at T1 and T3. Sample items from the SWLS include 3. I am satisfied with my life, and 5. If I could live my life over, I would change almost nothing.

\section{Results}

\subsection{Preliminary Analyses}

Descriptive statistics and correlations are provided in Table 1. Perceived good life coherence was not correlated with baseline autonomous motivation but was moderately correlated with autonomous goal motivation at time two and strongly correlated with SWB at both baseline and time 3. Preliminary pairwise comparisons showed that, on average, participants' SWB decreased from beginning of the year $(M=4.61, S D=0.81)$ to the end of the academic year (T3: $M=4.50, S D=0.91), t(200)=-2.28, p=0.024$, and that, on average, participants' autonomous goal motivation did not change from beginning of the year $(M=5.30, S D=0.85)$ to the middle of the year $(M=5.42, S D=0.84), t(219)=1.32$, $p=0.1868$.

\subsection{Serial Mediation Model}

To examine whether perceived good life coherence was associated with changes towards greater SWB through increases in autonomous goal and goal progress, we estimated a serial mediation model using the Hayes PROCESS macro for SPSS (2012). The serial mediation was chosen for theoretical reasons and consistency with prior research findings, since many studies have demonstrated that goal motivation is a significant predictor and antecedent of subsequent goal progress (Holding et al., 2017; Koestner et al., 2008). Baseline autonomous goal motivation and SWB were entered as covariates. T1 perceived good life coherence was entered as the predictor $(\mathrm{X})$, T2 autonomous goal motivation was entered as the first mediator (M1), T2 goal progress was entered as the second mediator (M2), and T3 SWB was entered as the outcome (Y). Bias-corrected bootstrapped confidence intervals $(k=10,000)$ were generated for each of the three possible indirect effects in this model (i.e., $\mathrm{X} \rightarrow \mathrm{M} 1 \rightarrow \mathrm{Y}, \mathrm{X} \rightarrow \mathrm{M} 2 \rightarrow \mathrm{Y}$, and $\mathrm{X} \rightarrow \mathrm{M} 1 \rightarrow \mathrm{M} 2 \rightarrow \mathrm{Y}$ ). An indirect effect was considered significant if the $95 \% \mathrm{CI}$ did not contain zero.

Table 1 Descriptive statistics and correlations

\begin{tabular}{lllllllll}
\hline Measure & $M$ & $S D$ & 1 & 2 & 3 & 4 & 5 & 6 \\
\hline 1. T1 Perceived Good Life Coherence & 4.18 & 1.52 & & & & & & \\
2. T1 Autonomous Goal Motivation & 5.30 & 0.85 & .11 & & & & & \\
3. T2 Autonomous Goal Motivation & 5.42 & 0.84 & $.23 * * *$ & $.42^{* * *}$ & & & & \\
4. T2 Goal Progress & 4.27 & 1.14 & $.34 * * *$ & $.14^{*}$ & $.25^{* * *}$ & & & \\
5. T1 SWB & 4.61 & 0.81 & $.51^{* * *}$ & $.15^{*}$ & $.28^{* * *}$ & $.36^{* * *}$ & \\
6. T3 SWB & 4.50 & 0.91 & $.50^{* * *}$ & .07 & .11 & $.39^{* * *}$ & $.58^{* * *}$ \\
Note. SWB = Subjective Well-Being & & & & & & & & \\
\hline
\end{tabular}

$* * * p<.001 * * p<.01 * p<.05$ 
Results from the mediation analysis showed that baseline good life coherence was a significant predictor of $\mathrm{T} 2$ autonomous motivation (controlling for baseline autonomous motivation) $b=0.11, S E=04, t=3.07, p<0.001,95 \% C I[0.04,0.18]$, Model $R^{2}=0.046$. In turn, changes in autonomous goal motivation were positively associated with T2 goal progress, $b=0.32, S E=0.09, t=3.28, p<0.001,95 \% C I[0.13,0.50]$, Model $R^{2}=0.172$, such that experiencing greater autonomous motivation for one's goals was positively associated with reporting goal progress. Finally, T2 goal progress was a significant predictor of T3 SWB, controlling for SWB at baseline, $b=0.15, S E=0.05, t=3.18, p<0.001,95 \%$ $C I[0.06,0.25]$, Model $R^{2}=0.421$, suggesting that participants' progress on personal goals during the middle of the academic year was associated with increases in SWB by the end of the academic year.

Next, we examined the total, indirect, and direct effects. The total effect of autonomous motivation on end-of-semester goal progress was significant at $b=0.16, S E=0.04, t=4.21$, $p<0.001,95 \% C I[0.08,0.24]$. Partially standardized indirect effects (e.g., $a b / s_{Y}$ for single mediator) were calculated in order to provide an assessment of effect size, and represent the standard deviation change in the dependent variable for a unit change in the independent variable; this measure was selected as it has been shown to be efficient, relatively unbiased, and more reliable than traditional measures (e.g., $P m=$ proportion mediated) for samples under 500 participants (Miočević et al., 2018).

The full serial mediation model is presented in Fig. 1, with standardized regression coefficients and standard errors reported for each of the constituent paths. All of the constituent paths were significant, including the direct effect of perceived good life coherence, demonstrating partial mediation, $b=0.14, S E=0.04, t=3.59, p<0.001,95 \% C I[0.06,0.22]$ The first indirect effect, from perceived good life coherence to autonomous goal motivation to SWB, was significant but not in the expected direction, est $=-0.02, S E=0.01,95 \%$ $C I[-0.050,-0.002]$. The direction of this effect is attributable to the surprising negative relation between mid-year autonomous goal motivation and end-of-year subjective wellbeing. The second indirect effect, from perceived good life coherence to goal progress to SWB, was significant and in the expected direction, est $=0.04, S E=0.02,95 \%$ CI $[0.012$, 0.074]. The third indirect effect tested the full serial mediation model from perceived good life coherence to autonomous goal motivation to SWB and was significant in the expected direction, $e s t=0.005, S E=0.004,95 \% C I[0.001,0.017]$. As the standard deviation of $\mathrm{T} 3$ SWB was close to $1(S D=0.91)$, the partially standardized effects are approximately the same as the estimates reported here, indicating that a unit change in each indirect effect

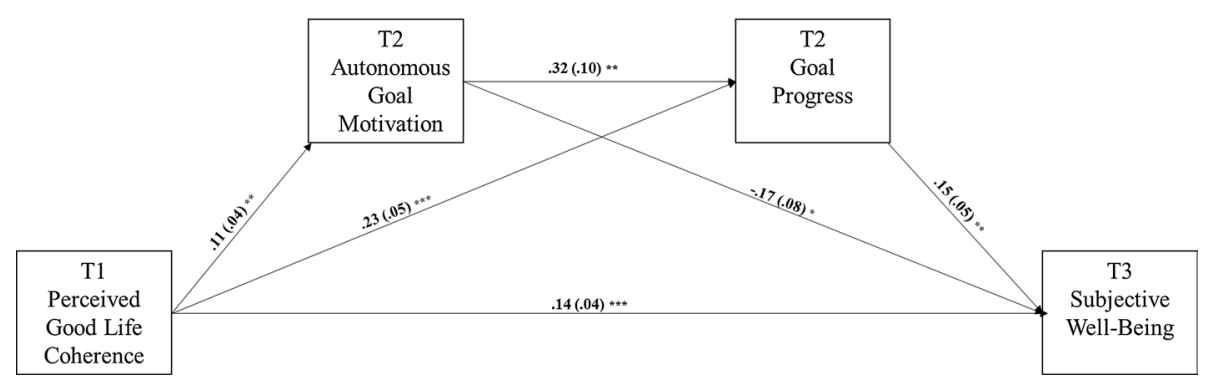

Fig. 1 Serial Mediation Model. Note. Standardized regression coefficients are reported, and values in parentheses are standard errors (i.e., $\beta$ (SE)). This model controlled for baseline (T1) Subjective Well-Being and baseline autonomous goal motivation. $* * * p<.001 * * p<.01 * p<.05$ 
results in a $0.02 \mathrm{SD}$ reduction in T3 SWB, a $0.04 \mathrm{SD}$ increase in SWB, and a $0.005 \mathrm{SD}$ increase in SWB, respectively. Taken together, these results support the hypothesis that individuals who perceive themselves as living in line with their vision of the good life experience higher subjective well-being over time in part because they set more autonomous goals over time and make more progress on their goals.

\section{General Discussion}

The primary aim of this study was to examine whether perceiving oneself to be living coherently with personal conceptions of the good life was associated with greater autonomous goal motivation and, subsequently, greater goal progress and greater SWB over time. We theorized personal good life philosophies to be situated fairly high in the motivational hierarchy and from this hypothesized that individuals who assessed their current lives as coherent with their ideas of the good life would also experience better motivational outcomes.

Indeed, results of the present study suggested that perceiving oneself to live in coherence with one's personal philosophy of the good life was associated with a series of positive motivational outcomes that centred around "doing better" and "feeling good"; two common determinants of eudaemonia. As Ryan et al. (2006) argue, positive affect is both a correlate and consequence of eudaemonia or 'living well' (p. 141). As a product of pursuing meaningful goals, individuals will experience greater pleasure (Ryan \& Deci, 2001). We suggest that perceived good life coherence demonstrates the sort of eudaemonia described by Ryan and colleagues - that perceiving oneself as living coherently in terms of one's own philosophy of flourishing is associated with actual flourishing in terms of doing well (goal progress) and feeling good (change towards greater SWB). It could also be argued that good life coherence acts as a measure of basic hedonia, in which individuals are simply reporting the extent to which their expectations are being met. Another argument could be made that good life coherence acts as an indirect measure of basic need fulfillment due to its close association with autonomous motivation. Future research could further examine the directional nature of this relationship and the extent to which good life coherence is associated with autonomy, competence and relatedness.

Our findings also suggest that those able to follow their own life philosophies of the good life or perceive coherence between their current life and their ideal of the good life tended to report goals that were endorsed with greater autonomous motivation (Sheldon, 2014). It is noteworthy that good life coherence and baseline autonomous motivation for personal goals were not correlated, but that this relationship became significant over time. Specifically, autonomous goal motivation and increases in autonomous motivation both predict increases in goal progress. While the direction of this effect needs to be established with experimental replication, the relationship between good life coherence and autonomous motivation is consistent with previous research that has found traits that are associated with self-insight, such as "proactive personalities" (Bateman \& Crant, 1993) and "positive core evaluations" (Judge, et al., 2005) tend to produce greater autonomous functioning. Although we did not directly examine whether self-insight is a necessary mechanism in achieving greater perceived good life coherence, the process and correlates of perceived good life coherence are comparable. Namely, both require an integration of abstract beliefs with more concrete behaviour and are associated with increases in autonomous regulation. Secondly, we hypothesized that greater perceived good life coherence, 
if associated with greater autonomous motivation, would also be associated with greater goal progress and subsequently higher SWB over time. This result replicates Sheldon and Elliott's (1998) well-established finding that increased autonomous motivation predicts enhanced goal progress over time, and that increases in goal progress are associated with enhanced well-being (Klug \& Maier, 2015; Koestner et al, 2002; Sebire et al., 2009). Significantly, these findings also shed light on a novel antecedent to the spiral of positive motivational outcomes.

Although the present study is observational, future research could examine whether good-life coherence serves as an intervention to enhance autonomous goal striving. Perceived good-life coherence may serve as a promising method to increase autonomous goal striving- by helping individuals to identify discrepancies between their highest ideals for living and their current reality. This may prompt volitional goal striving similar to how mental contrasting promotes goal prioritization (Oettingen, 2012). In mental contrasting, individuals are first prompted to visualize their wish for the future and then contrast that image with the obstacles in their present reality that stand in the way of fulfilling the wish. Mental contrasting has been shown to enhance goal commitment when the obstacles are deemed surmountable, while promoting disengagement from goals where the obstacles in one's present reality are deemed insurmountable (Oettingen, 2012). Thus, while mental contrasting focuses on enhancing motivation and commitment for a specific wish, the "good life coherence" exercise may help to enhance autonomous motivation for a series of goals that target different lower-level components of the overall "good life" vision.

Future research is also needed to determine whether specific individual differences, such as trait mindfulness or trait self-control, explain meaningful variance in perceiving good life coherence. For example, a recent series of studies found that trait mindfulness was associated with setting more autonomous goals which was in turn associated with greater goal progress (Smyth et al., 2020). Likewise, a longitudinal study with university students found that individual differences in self-control promoted changes in motivation for personal goals, with individuals higher in self-control tending to feel more volitional in their goal pursuit over time (Holding et al., 2019). Thus, future studies examining good life coherence should control for various individual differences that may promote or enhance self-insight.

The central concern of this study, to investigate personal philosophies, was inspired by King's (2001) suggestion to examine philosophies of life. Notably, the good life shares some conceptual overlap with King's own construct of Best Possible Selves (BPS). Like the good life, possible selves also occupy a high position in the goal hierarchy and, subsequently, offer reference values to facilitate lower-level goals (Markus \& Ruvulo, 1989, p. 213). Furthermore, in most BPS research, participants are asked to write, in narrative form, their own idea of their best possible future. This is similar to the measures used in the present study to capture personal philosophies of the good life. King has also found that this intervention has led to greater SWB (King, 2001, p. 804). Although the present study is observational rather than interventional, our results extend previous BPS literature by offering 'good-life coherence' as a new measure. Specifically, the present study is distinct from previous possible selves' research due to (1) the minimized importance of the self when discussing the good life and (2) a lessened focus on the future. By asking individuals to articulate their personal conception of the good life, we hoped to provide a prompt that requires a greater level of abstraction and that is not necessarily future oriented, capturing instead abstract principles and system values. Our findings suggest that these higherorder beliefs and values, when reflected in perceived current functioning, are associated with greater autonomous motivation, goal progress, and SWB. Future research is needed to 
assess whether a similar pattern of results is obtained when individuals describe and rate their current life's coherence with their conception of their "best possible selves".

'Good-life coherence' is also similar in form and outcome to other measures that are theorized to capture higher-order values. Measures such as possible futures (Sheldon \& Kasser, 1995) and life growth goals (Bauer \& McAdams, 2004), despite varying in time and abstraction, are regularly applied in personality coherence research to examine cognitive representations of desirable or undesirable outcomes that individuals are committed to attain or avoid (Milyavskaya \& Werner, 2018, p. 163). However, asking individuals to articulate their view of the good life is still theoretically distinct enough from these others to deserve merit as a new measure. For example, whereas Sheldon \& Kasser's 1995 study offered 'possible futures' categories for the participants to select, the present study instead offers space for the narrative richness evident in written articulations of the good life. This use of narrative writing is more clearly reflected in 'life growth goals' which are written paragraphs that "reveal not only what people want most in life but also the reasons for those goals" (Bauer \& McAdams, 2010, p. 762). One important theoretical distinction, however, is that in "life growth goal" studies, the participants were prompted to write about two major goals in life (Bauer \& McAdams, 2004, p. 117; Bauer \& McAdams, 2010, p. 764). As previously discussed, Aristotle considers the good life to be the ultimate goal. Hence, even hierarchically high life goals may serve a subordinate role in order to achieve the good life. Furthermore, through asking individuals to articulate their personal philosophy of the good life rather than life goals, this present study instead attempts to examine abstract beliefs and values rather than goals that are theorized to be guided by such values. Nevertheless, future research is warranted to determine whether the outcomes of assessing good-life coherence differ significantly to conceptually related constructs.

\subsection{Limitations}

This research was not without limitations. Firstly, our study composed its findings around a sample of students that were all attending the same North American university, which is not necessarily representative of the general population. This limits the generalizability of our findings and warrants replication in samples of different ages and backgrounds. Notably, the results were primarily drawn from an age group that belongs to the developmental stage of emerging adulthood. Individuals in this stage, which is characterized by identity exploration and attempts to form future visions of one's life, may offer less stable good life statements than statements written in later stages (Arnett, 2000). Future research could explore the good life statements and good life coherence across different developmental stages.

Secondly, the correlational design of this study precludes us from making any causal inferences or excluding the possibility of confounding variables. Thirdly, although we hypothesized that individuals that expressed greater perceived good life coherence also demonstrated greater self-insight, the present study did not specifically examine this assumption. Future research could examine whether perceived good life coherence does require greater self-insight by measuring whether perceived good life coherence was associated with other measures of self-insight.

Another limitation in this study is the lack of an objective measure for assessing whether participants were living coherently with their philosophy of the good life. We cannot claim that greater perceived good life coherence demonstrated actual good life coherence as only self-reported assessments were measured. Likewise, the vagueness and brevity of the 
instructions for writing about the good life may be a limitation on the current findings. Future research could involve more elaborate instructions for writing about the good life, as well as holistic measures that go beyond self-reports, such as the use of experiencesampling measures and informant reports. Importantly, future studies could also re-assess participants' view of the good life and measure to what extent the definition changes over time. It is also not apparent if the actual process of having participants write out their personal philosophies is necessary in capturing perceived good life coherence and if, instead, simply asking participants to rate the extent to which they are living their idea of the good life would result in similar findings. Future research could use an experimental design to determine if there is a significant difference.

Finally, the reported indirect effects were all relatively small as indicated by the partially standardized indirect effects. This is particularly true of the overall indirect effect of the full serial mediation model (i.e., perceived good life coherence $\rightarrow$ autonomous motivation $\rightarrow$ goal progress $\rightarrow$ SWB), where the confidence interval nearly contained zero (i.e., lower bound $=0.001)$. This is unsurprising, as mediation effects are often small, and particularly so when multiple mediators and changes over time are included (e.g., Walters, 2019). Nonetheless, caution should be taken in interpreting these findings; replication is warranted, and future research may examine alternative models.

\section{Conclusion}

The focus of this study was to examine this process of following one's conception of the good life as a worthy endeavour. Our results suggest that when individuals assess themselves as following their own philosophy of living well, they tend to experience greater autonomous goal motivation, goal progress and SWB. In other words, perceiving oneself to be living coherently with personally endorsed higher values is associated with better living; a conclusion best reflected in Schwartz's observation that your values are one of the drivers of what you perceive to be the good life (1992). Importantly, this study has also demonstrated the significance of autonomy and the freedom to make decisions in the process of following one's good life; a key idea reflected in Carl Roger's view so many years ago; that when the individual is inwardly free, he chooses as the good life this process of becoming (p. 195, 1961).

\section{Appendix 1: Sample of Good Life Statements}

\footnotetext{
The good life would be me working at a job that I love, that interests me and challenges me. More importantly, I want to love, be loved, have a family and be able to provide comfortably for them

The "good life" is being able to make the optimal use of my talents, continually be intellectually stimulated, and feel at home in my community (however narrowly or broadly conceived this "community" might be). It entails maintaining a consistent sense of gratitude and interconnectedness with God and contributing actively to His vision for the flourishing of the world such that many people can experience His love

Being able to relax with family and the people you love the most. Work should be satisfying and helpful to the world, and leisure time can be spent following personal goals and dreams
} 
"The good life" to me means being financially stable, working at a job I am passionate about and being happy with the relationships I have with friends and family. With the caveat, that the "good life" includes some years as a stay-at-home mom and taking care of my children

Having a routine, working at a job that feels fulfilling, having enough money that you don't have to worry about money. Having a family that loves you, and close friends you spend time with and do fun things with

The good life is being happy and having loving relationships with partners, family, and friends. The greatest thing one could do would be to contribute to the well-being of the environment and therefore, society

I think the good life means you wake up in the morning actually wanting to go to your job/occupation, whether it be because of the job itself, the people you work with, the purpose for which you work, etc

I think the good life also means being comfortable and happy in your material home and feeling fulfilled by the relationships you have and the things you do 'for fun'

I would consider the good life to be a life in which I achieve happiness, whether that be through financial success, success in relationships, family, or love, or success in being a good person, I believe my best life is the one where I find happiness

Live in the country and have a garden of my own with a golden retriever, and to be comfortable financially, being fulfilled in my work helping others (as a nurse). Family is also extremely important to me, so I desire a life-time marriage and several children

the good life is having the financial means to achieve my basic needs and live comfortably, but not necessarily lavishly and to be surrounded by close friends and family. it also involves doing meaningful work and not being anxious or depressed

The good life is when all my needs are met enough so that I don't need to be constantly thinking about how to financially support myself. It is also when you are working or studying in an area that is equally interesting and self-fulfilling

Funding Social Sciences and Humanities Research Council of Canada, Grant Number (435-2014-0671). Fonds de Recherche du Québec-Société et Culture, Grant Number (196443)

\section{Declarations}

Conflict of interest We have no known conflict of interest to disclose.

Ethical Approval All procedures performed in studies involving human participants were in accordance with the ethical standards of the institutional and/or national research committee and with the 1964 Helsinki declaration and its later amendments or comparable ethical standards.

Informed Consent Informed consent was obtained from all individual participants included in the study.

\section{References}

Arnett, J. J. (2000). Emerging adulthood. A theory of development from the late teens through the twenties. The American Psychologist, 55(5), 469-480.

Bateman, T. S., \& Crant, J. M. (1993). The proactive component of organizational behavior: A measure and correlates. Journal of Organizational Behavior, 14, 103-118.

Bauer, J. J., \& McAdams, D. P. (2004). Growth goals, maturity, and well-being. Developmental Psychology, 40(1), 114-127. https://doi.org/10.1037/0012-1649.40.1.114

Bauer, J. J., \& McAdams, D. P. (2010). Eudaimonic growth: Narrative growth goals predict increases in ego development and subjective well-being 3 years later. Developmental Psychology, 46(4), 761-772. https://doi.org/10.1037/a0019654 
Baumeister, R. F., Vohs, K. D., Aaker, J. L., \& Garbinsky, E. N. (2013). Some key differences between a happy life and a meaningful life. The Journal of Positive Psychology, 8(6), 505-516. https://doi. org/10.1080/17439760.2013.830764

Flanagan, O. (2007). The really hard problem: Meaning in a material world. MIT Press.

Fournier, M. A., Di, D. S. I., Quitasol, M. N., Dong, M., \& Weststrate, N. M. (2015). Toward a unified science of personality coherence. Canadian Psychology, 56(2), 253-262. https://doi.org/10.1037/ cap0000022

Holding, A.C. \& Koesnter, R. (2021). A self-determination theory perspective on how to choose, use and lose personal goals. (Chapter for Oxford Handbook of Educational Psychology, Edited by Johnmarshall Reeve).

Holding, A. C., Hope, N. H., Harvey, B., Marion Jetten, A. S., \& Koestner, R. (2017). Stuck in limbo: Motivational antecedents and consequences of experiencing action crises in personal goal pursuit. Journal of Personality, 85, 893-905.

Holding, A., Hope, N., Verner-Filion, J., \& Koestner, R. (2019). In good time: A longitudinal investigation of trait self-control in determining changes in motivation quality. Personality and Individual Differences, 139, 132-137.

Hope, N. H., Holding, A. C., Verner-Filion, J., Sheldon, K. M., \& Koestner, R. (2019). The path from intrinsic aspirations to subjective well-being is mediated by changes in basic psychological need satisfaction and autonomous motivation: A large prospective test. Motivation and Emotion, 43, 232-241.

Judge, J. A., Bono, J. E., Erez, A., \& Locke, E. A. (2005). Core self-evaluations and job and life satisfaction: The role of self concordance and goal attainment. Journal of Applied Psychology, 90, 257-268.

King, L. A. (2001). The health benefits of writing about life goals. Personality and Social Psychology Bulletin, 27(7), 798-807.

Klug, H. J. P., \& Maier, G. W. (2015). Linking Goal Progress and Subjective Well-Being: A Meta-analysis. Journal Happiness Studies, 16, 37-65. https://doi.org/10.1007/s10902-013-9493-0

Koestner, R., Lekes, N., Powers, T. A., \& Chicoine, E. (2002). Attaining personal goals: Self- concordance plus implementation intentions equals success. Journal of Personality and Social Psychology, 83(1), 231.

Koestner, R., Otis, N., Powers, T. A., Pelletier, L., \& Gagnon, H. (2008). Autonomous motivation, controlled motivation, and goal progress. Journal of Personality, 76(5), 1201-1230. https://doi.org/10. 1111/j.1467-6494.2008.00519.x

Kraut, R. (2018). Aristotle's Ethics. Retrieved from https://plato.stanford.edu/archives/sum2018/entries/ aristotle-ethics/

Markus, H., \& Ruvolo, A. (1989). Possible selves: Personalized representations of goals. In L. A. Pervin (Ed.), Goal concepts in personality and social psychology (pp. 211-241). Lawrence Erlbaum Associates Inc.

McAdams, D. P. (2018). Art and science of personality development. The Guilford Press.

Milyavskaya, M., Inzlicht, M., Hope, N., \& Koestner, R. (2015). Saying "no" to temptation: Want-to motivation improves self-regulation by reducing temptation rather than by increasing self-control. Journal of Personality and Social Psychology, 109, 677.

Milyavskaya, M., \& Werner, K. M. (2018). Goal pursuit: Current state of affairs and directions for future research. Canadian Psychology/psychologie Canadienne, 59(2), 163-175. https://doi.org/10.1037/ cap0000147

Miočević, M., O’Rourke, H. P., MacKinnon, D. P., \& Brown, H. C. (2018). Statistical properties of four effect-size measures for mediation models. Behavior Research Methods, 50, 285-301. https://doi. org/10.3758/s13428-017-0870-1

Oettingen, G. (2012). Future thought and behaviour change. European Review of Social Psychology, 23, $1-63$.

Park, N., \& Peterson, C. (2009). Achieving and Sustaining a Good Life. Perspectives on Psychological Science, 4(4), 422-428. https://doi.org/10.1111/j.1745-6924.2009.01149.x

Powers, W. T. (1973). Behavior: The control of perception. Aldine.

Rogers, C. R. (1961). On becoming a person: A therapists view of psychotherapy. Houghton Mifflin.

Ryan, R.M. and Deci E. L. (2001) On happiness and human potentials: A review of research on hedonic and eudaimonic well-being'. In S. Fiske (ed.), Annual Review of Psychology (Annual Reviews Inc., Palo Alto, CA), Vol. 52, pp. 141-166.

Ryan, R. M., \& Deci, E. L. (2017). Self-determination theory: Basic psychological needs in motivation, development, and wellness. Guilford Press.

Ryan, R. M., Huta, V., \& Deci, E. L. (2006). Living well: A self-determination theory perspective on eudaimonia. Journal of Happiness Studies, 9(1), 139-170. https://doi.org/10.1007/s10902-006-9023-4 
Schlegel, R. J., Hicks, J. A., King, L. A., \& Arndt, J. (2011). Feeling like you know who you are: Perceived true self-knowledge and meaning in life. Personality \& Social Psychology Bulletin, 37(6), 745-756. https://doi.org/10.1177/0146167211400424

Schwartz, S. H. (1992). Universals in the context and structure of values: Theoretical advances and empirical tests in 20 Countries (Vol. 25). Academic Press Inc.

Sebire, S. J., Standage, M., \& Vansteenkiste, M. (2009). Examining intrinsic versus extrinsic exercise goals: Cognitive, affective, and behavioral outcomes. Journal of Sport and Exercise Psychology, 31(2), 189210. https://doi.org/10.1123/jsep.31.2.189

Sheldon, K. M. (2004). Optimal human being: An integrated multilevel perspective. Lawrence Erlbaum.

Sheldon, K. (2014). Becoming oneself: The central role of self-concordant goal selection Personality and Social Psychology Review. An Official Journal of the Society for Personality and Social Psychology, 18(4), 349-365. https://doi.org/10.1177/1088868314538549

Sheldon, K. M., \& Elliot, A. J. (1998). Not all personal goals are personal: Comparing autonomous and controlled reasons as predictors of effort and attainment. Personality and Social Psychology Bulletin, 24, 546-557.

Sheldon, K., \& Kasser, T. (1995). Coherence and congruence: Two aspects of personality integration. Journal of Personality and Social Psychology, 68, 531-543. https://doi.org/10.1037/0022-3514.68.3.531

Smyth, A. P., Werner, K. M., Milyavskaya, M., Holding, A., \& Koestner, R. (2020). Do mindful people set better goals? Investigating the relation between trait mindfulness, self-concordance, and goal progress. Journal of Research in Personality, 88, 104015.

Walters, G. D. (2019). Why are mediation effects so small? International Journal of Social Research Methodology, 22(2), 219-232.

Wong, P. T. P. (2011). Positive psychology 20: Towards a balanced interactive model of the good life. Canadian Psychology/psychologie Canadienne, 52(2), 69-81. https://doi.org/10.1037/a0022511

Publisher's Note Springer Nature remains neutral with regard to jurisdictional claims in published maps and institutional affiliations. 